\title{
Silibinin induces apoptosis through inhibition of the mTOR-GLI1-BCL2 pathway in renal cell carcinoma
}

\author{
ZHENKUN MA, WEI LIU, JIN ZENG, JIANCHENG ZHOU, PENG GUO, HONGJUN XIE, \\ ZHAO YANG, LONG ZHENG, SHAN XU, XINYANG WANG, LUKE S. CHANG, DALIN HE and LEI LI
}

\author{
Department of Urology, The First Affiliated Hospital of Xi'an Jiaotong University, Xi'an, Shaanxi 710061, P.R. China
}

Received May 8, 2015; Accepted July 22, 2015

DOI: 10.3892/or.2015.4224

\begin{abstract}
The downstream transcriptional factor of the hedgehog $(\mathrm{Hh})$ pathway, GLI family zinc finger 1 (GLI1), plays a crucial role in regulating tumor progression. In the present study, we demonstrated that silibinin, a natural flavonoid antioxidant isolated from extracts of the milk thistle herb, exerts its anticancer capabilities by restraining GLI1 function in renal cell carcinoma (RCC) cells in vitro and in vivo. In the present study, we confirmed that silibinin induced growth inhibition of RCC through caspase-dependent apoptosis and downregulation of GLI1 and BCL2, which could be partially reversed by GLI1 overexpression. Moreover, we determined that the decreased GLI1 expression by silibinin was mediated by the mammalian target of rapamycin (mTOR) pathway. The in vivo mouse xenograft study also showed that silibinin significantly reduced RCC tumor growth and specifically targeted the mTOR-GLI1-BCL2 signaling pathway. In conclusion, our findings demonstrated for the first time that silibinin induces apoptosis of RCC cells through inhibition of the mTOR-GLI1-BCL2 pathway. These findings also indicate that GLI1 is a novel regulator for the potential therapeutic application of silibinin against RCC.
\end{abstract}

\section{Introduction}

Renal cell carcinoma (RCC) is one of the most common malignant tumors of the urinary system, accounting for $80-90 \%$ of kidney neoplasms. The American Cancer Society estimated that the number of new cancer cases and deaths caused by cancer of the kidney and renal pelvis were 63,920 and 13,860 in 2014 in the US (1). Surgical resection is considered to be the first choice for the curative treatment of localized RCC and some locally advanced RCC. However, $25-30 \%$ patients

Correspondence to: Professor Lei Li, Department of Urology, The First Affiliated Hospital of Xi'an Jiaotong University, 277 Yanta West Road, Xi'an, Shaanxi 710061, P.R. China

E-mail: lilydr@163.com

Key words: renal cell carcinoma, silibinin, apoptosis, GLI family zinc finger 1, mammalian target of rapamycin initially present with metastases, and a substantial part of patients have subclinical metastases at that time $(2,3)$. Some patients undergoing surgical treatment relapse to metastatic renal cell carcinoma ( $\mathrm{mRCC})$. $\mathrm{mRCC}$ is usually resistant to radiotherapy and chemotherapy, while immunotherapy shows limited response rates of $15-20 \%$ (4-6). Therefore, understanding the mechanisms involved in the progression of RCC especially mRCC and exploring more effective targeted therapies are urgently needed.

The hedgehog $(\mathrm{Hh})$ pathway was firstly emphasized in embryonic developmental studies $(7,8)$. Recent research has demonstrated that the $\mathrm{Hh}$ pathway is constitutively activated in cancer compared with normal tissue and plays a crucial role in cancer progression (9-13). Inhibition of Hh signaling was found to significantly induce apoptotic cell death in pancreatic cancer cell lines both in vitro and in vivo (9). Hh signaling-mediated survival of gastric cancer cells is known to be associated with the regulation of apoptosis inhibition protein BCL2 (12). Selective downregulation of GLI family zinc finger 1 (GLI1) by antisense oligodeoxynucleotides results in decreased BCL2 expression and cancer cell survival (13). Clinical trials suggest benefits for patients administered specific Hh pathway inhibitors. GDC-0449, a small-molecule inhibitor of SMO, has shown encouraging antitumor activity in locally advanced or metastatic solid tumors in two separated phase I trials $(14,15)$. Another Hh inhibitor itraconazole decreased cancer cell proliferation by $45 \%$, Hh pathway activity by $65 \%$, and reduced the tumor area by $24 \%$ in phase II trials (16). Dormoy et al also reported that the sonic Hh signaling pathway is reactivated in RCC compared with normal tissue, and inhibition of this pathway dramatically decreases tumor cell proliferation and induces apoptosis in vitro and in vivo (17). Thus, the Hh pathway may be a promising target for RCC especially mRCC therapy.

Silibinin is a natural flavonoid which is widely used for the treatment of drug- or alcohol-induced liver injury and cirrhosis. Recent studies have shown the significant anticancer activity of silibinin. For many tumors such as prostate $(18,19)$, bladder $(20,21)$, lung $(22)$ and colon $(23,24)$ cancers, silibinin exhibits growth inhibitory and anti-inflammatory effects, cell cycle arrest, apoptosis induction, chemosensitization, inhibition of angiogenesis, reversal of multi-drug resistance and inhibition of invasion and metastasis, which involves regulation of receptor tyrosine kinases, the androgen receptor, and 
cell cycle regulatory and apoptotic signaling pathways (25). Cheung et al showed that oral administration of silibinin suppressed local and metastatic tumor growth in an orthotopic xenograft model of RCC. This anti-neoplastic action of silibinin might involve insulin-like growth factor-binding protein 3 (IGFBP-3) (26). Our previous studies demonstrated the apoptosis induction and metastatic inhibitory effects of silibinin against RCC by targeting the epidermal growth factor receptor (EGFR) pathway $(27,28)$. Recently, we found that autophagy induction by silibinin positively contributes to its anti-metastatic capacity via the adenosine 5'-monophosphate-activated protein kinase (AMPK)/mammalian target of rapamycin (mTOR) pathway in RCC cells (29). However, whether the Hh pathway is regulated by silibinin followed by induction of apoptosis remains to be explored.

In the present study, 769-P, 786-O, OS-RC-2 (cell lines derived from primary clear cell adenocarcinoma, which have the similar genetic and molecular features of RCC) and ACHN (a cell line derived from the malignant pleural effusion, which has the similar genetic and molecular feature of mRCC) cell lines were applied as the model system. We first document that the mTOR-GLI1-BCL2 pathway is crucial for silibinin-induced apoptosis in RCC cells, and imply that GLI1 is a novel regulator for the potential therapeutic application of silibinin against RCC.

\section{Materials and methods}

Cell culture and reagents. Human RCC cell lines 769-P, 786-O, ACHN and OS-RC-2 were purchased from the American Type Culture Collection (ATCC; Manassas, VA, USA), and cultured in Dulbecco's modified Eagle's medium (DMEM)/F-12 medium supplemented with 10\% fetal bovine serum (FBS) (Gibco-BRL, New York, NY, USA) at $37^{\circ} \mathrm{C}$, in humidified air containing $5 \% \mathrm{CO}_{2}$. Silibinin, cyclopamine, LY294002, rapamycin and 3-(4,5-dimethylthiazol-2-yl)-2,5-diphenyltetrazolium bromide (MTT) were purchased from Sigma-Aldrich (St. Louis, MO, USA). Antibodies for western blot analysis against poly(ADP-ribose) polymerase (PARP), cleaved caspase-3, p-mTOR, mTOR, p-ERK, ERK, p-AKT (Thr308), p-AKT (Ser473) and AKT were purchased from Cell Signaling Technology, Inc. (Beverly, MA, USA). Anti-GLI1 was from Bioss, Inc. (Beijing, China). Anti-BCL2 was from Santa Cruz Biotechnology, Inc. (Dallas, TX, USA). Anti-glyceraldehyde 3-phosphate dehydrogenase (GAPDH) was purchased from KangChen Bio-tech, Inc. (Shanghai, China). Antibodies for immunohistochemistry against p-mTOR and BCL2 were from Abcam (Cambridge, MA, USA), and the antibody against GLI1 was from Santa Cruz Biotechnology, Inc.

Cell viability assay. Cell viability was measured by a tetrazolium-based assay. Briefly, cells were seeded in a 96-well plate and treated with doses of silibinin from 0 to $200 \mu \mathrm{M}$ for the indicated time. The medium was then removed and cells were incubated with $0.5 \mathrm{mg} / \mathrm{ml}$ MTT for $4 \mathrm{~h}$ and the formazan products were resolved with dimethyl sulfoxide (DMSO) (150 $\mu \mathrm{l} /$ well). The OD value of each well was measured by a microplate reader at a wavelength of $490 \mathrm{~nm}$. The experiments were performed in triplicate.
Colony formation assay. Cells were seeded in a 6-well plate (1,000 cells/well) and incubated for 48-72 $\mathrm{h}$, followed by treatment with different doses of silibinin. The mediums and drugs were replaced every 3 days. Ten days later when a single cell formed a colony ( $\geq 50$ cells), the plates were washed with phosphate-buffered saline (PBS), fixed in $10 \%$ formalin, and then stained with $0.1 \%$ crystal violet solution. Cell colony numbers were counted under a microscope. The experiments were performed in triplicate.

Quantitative detection of apoptosis. To evaluate the apoptosis induced by the reagents, flow cytometry was performed. Cells were treated with the indicated doses of silibinin for $48 \mathrm{~h}$, and collected for Annexin V and propidium iodide (PI) staining (Roche Diagnostics GmbH, Mannheim, Germany) following the manufacturer's instructions, and the apoptotic cells were detected and analyzed by flow cytometry (FACSCalibur; BD Biosciences, Franklin Lakes, NJ, USA).

Western blot analysis. Cell lysates were prepared in lysis buffer [10 mM of Tris- $\mathrm{HCl}(\mathrm{pH} 7.4), 150 \mathrm{mM}$ of $\mathrm{NaCl}$, $0.1 \%$ of SDS, $1 \mathrm{mM}$ of EDTA, $1 \mathrm{mM}$ of EGTA, $0.3 \mathrm{mM}$ of PMSF, $0.2 \mathrm{mM}$ of sodium orthovanadate, $1 \%$ of NP-40, $10 \mathrm{mg} / \mathrm{ml}$ of leupeptin and $10 \mathrm{mg} / \mathrm{ml}$ of aprotinin]. Proteins were separated by sodium dodecyl sulfate-polyacrylamide gel electrophoresis (SDS-PAGE) on 10 or $12 \%$ Tris-glycine gels, and transferred onto nitrocellulose membranes. The membranes were blocked with 5\% skim milk in TBS for $1 \mathrm{~h}$ at room temperature, and probed the with primary antibody overnight at $4^{\circ} \mathrm{C}$ followed by secondary antibody incubation for $1 \mathrm{~h}$ at room temperature. The protein expression was visualized with the ECL detection system or Odyssey infrared imaging system (Li-Cor Biosciences, Lincoln, NE, USA).

Reverse transcription and real-time PCR. Total RNA was isolated with RNAfast 200 reagents (Fastagen Biotechnology Co., Ltd., Shanghai, China) following the manufacturer's instructions and was quantitated by absorbance at $260 \mathrm{~nm}$. The RNA $(0.5 \mu \mathrm{g})$ sample was used for reverse transcription with PrimeScript ${ }^{\mathrm{TM}}$ RT Master Mix according to the manufacturer's instructions, and quantitative PCR was performed with SYBR-Green PCR Master Mix (both from Takara Bio, Inc., Dalian, China) and GAPDH mRNA was used as the internal control. The primer sequences were: GLI1 forward, 5'-GATG ATCCCACATCCTCAGTCC-3' and reverse, 5'-ACTTGCCA ACCAGCATGTCC-3'; GAPDH forward, 5'-ATGGGGAAGG TGAAGGTCGG-3' and reverse, 5'-GACGGTGCCATGGAA TTTGC-3'.

Plasmid, siRNA transfection. GLI1 cDNA was cloned into the pcDNA3.1 vector. Small interfering RNAs were designed and synthesized by Gene Pharma (Shanghai, China). Cells achieved $70-80 \%$ confluence for plasmid transfection or $30-50 \%$ confluence for siRNA transfection, and were transfected with X-tremeGENE HP DNA or X-tremeGENE siRNA transfection reagents (Roche Diagnostics $\mathrm{GmbH}$ ) for 2-3 days, and harvested for subsequent experiments.

Xenograft model. Cells (786-O) were mixed with Matrigel $(5: 1, \mathrm{v} / \mathrm{v})$ and injected subcutaneously into the right hind flank 
A
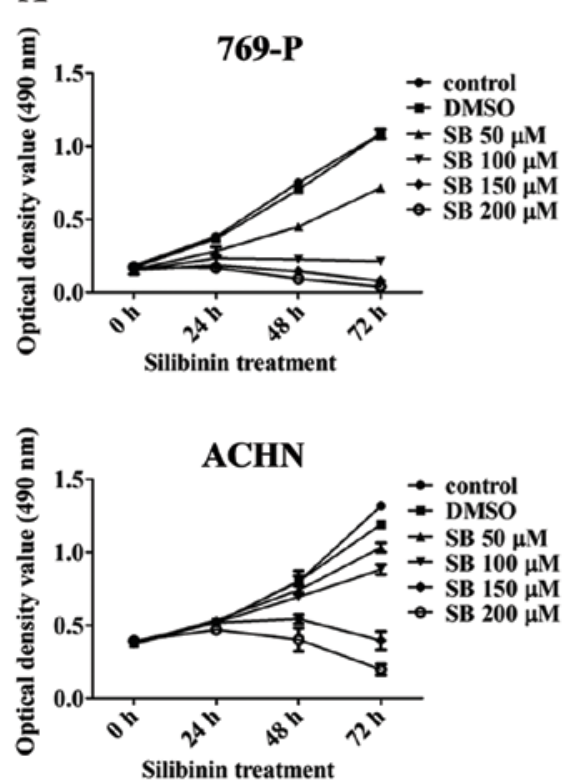

C

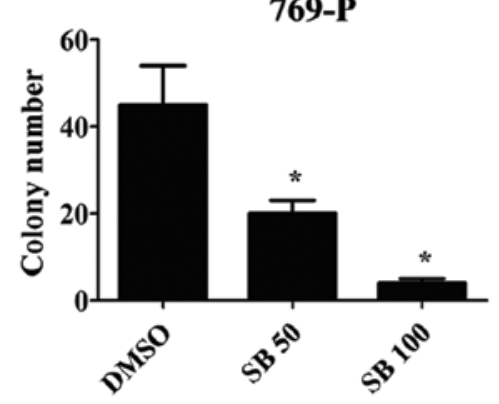

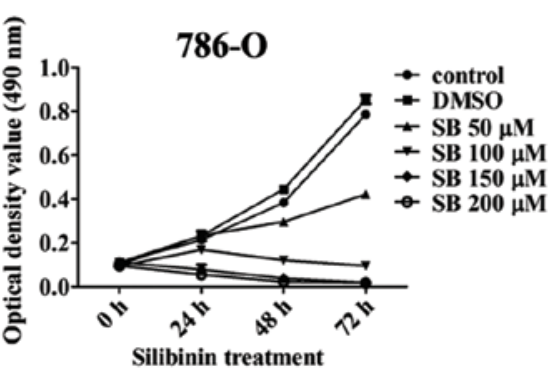

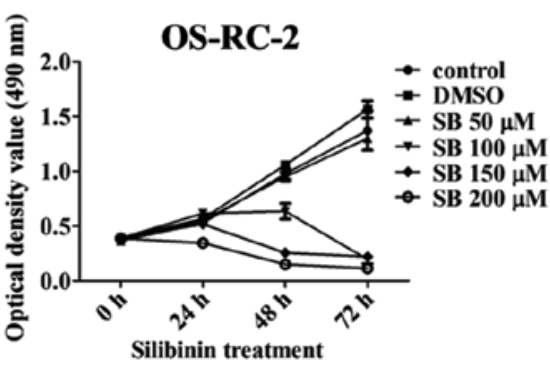

786-O

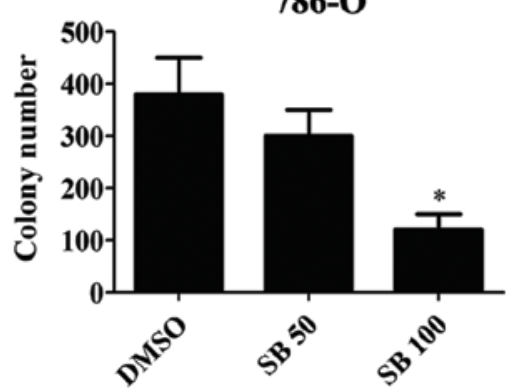

B

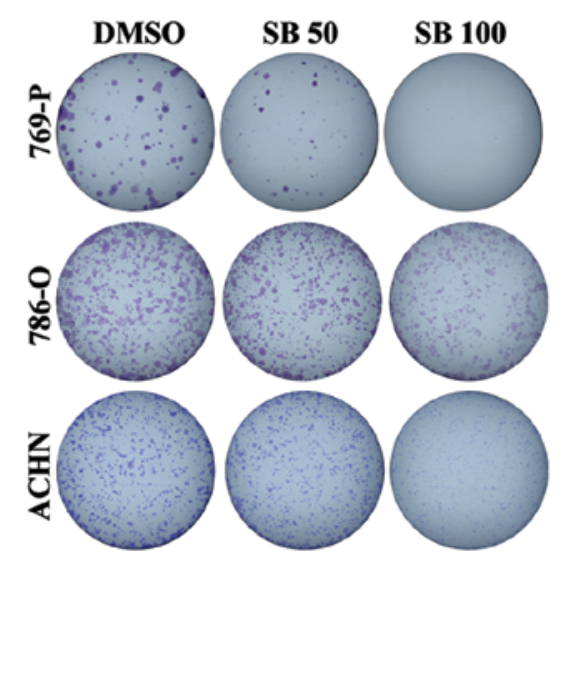

ACHN

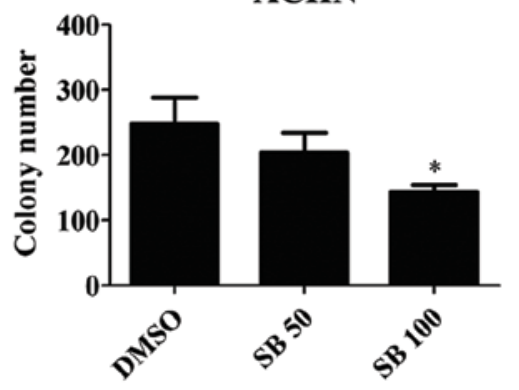

Figure 1. Silibinin inhibits the proliferation and colony formation of RCC cells. (A) RCC 769-P, 786-O, ACHN and OS-RC-2 cells were treated with different doses of silibinin (SB) $(50,100,150$ and $200 \mu \mathrm{M})$ or DMSO (control) for $0,24,48$ and $72 \mathrm{~h}$, and MTT assay was performed to detect cell viability. (B) The 769-P, 786-O and ACHN cells were treated with DMSO (control) or silibinin (50 and $100 \mu \mathrm{M}$ ), and the colony formation assay was performed after 10 days of treatment. The results were recorded by photographing. (C) Quantitative results of the colony numbers. The values represent the mean \pm SD of three independent experiments $\left({ }^{*} \mathrm{P}<0.05\right)$. RCC, renal cell carcinoma.

of male BALB/c (nu/nu) mice. Twelve days after injection, the mice were randomly divided into two groups (5 mice/group), and were fed by oral gavage with saline or silibinin $(200 \mathrm{mg} / \mathrm{kg})$. The volume of tumors were measured with a vernier caliper every three days. Thirty days after implantation, the mice were sacrificed and the tumors were weighed with electronic scales and fixed in $10 \%$ formalin and embedded in paraffin. Animal experiments were approved by the Institutional Animal Care and Use Committee of Xi'an Jiaotong University (permit no. SCXK2014-0155, 5 March 2014).

Immunohistochemistry. Immunohistochemical staining was performed with the EnVision ${ }^{\mathrm{TM}}$ system (Dako, Carpinteria, CA, USA), and the slices were de-paraffinized, rehydrated, followed by $5 \mathrm{~min}$ antigen retrieval, $10 \mathrm{~min}$ of endogenous enzyme block and incubated with the primary antibody overnight at $4^{\circ} \mathrm{C}$. Then the slices were incubated with EnVision-HRP secondary antibody for $1 \mathrm{~h}$, and the signals were detected by diaminobenzidine (DAB) followed by hematoxylin counterstaining. The results were observed by a microscope. Stained cells were quantified as the number of positive cells x 100/total number of cells in 10 random microscopic (magnification, $\mathrm{x} 200)$ fields in each slice.

Statistical analysis. All the statistical analyses were performed by GraphPad Prism version 5.0 software, and the Student's t-test was used for two-group comparisons. $\mathrm{P}<0.05$ was considered statistically significant.

\section{Results}

Silibinin inhibits the proliferation and colony formation of $R C C$ cells. To evaluate the effects of silibinin on RCC cells, four cell lines 769-P, 786-O, ACHN and OS-RC-2 were treated with different doses of silibinin. The results showed that silibinin significantly inhibited the proliferation of RCC cells in a dose- and time-dependent manner as detected by MTT assay (Fig. 1A). Similarly, silibinin treatment also decreased the colony numbers in the 769-P, 786-O and ACHN RCC cells as determined by the colony formation assay (Fig. 1B and C). 
A

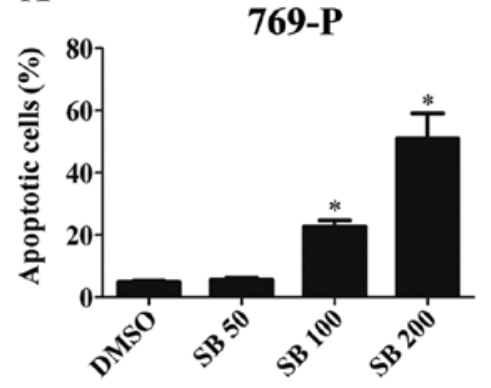

B

769-P

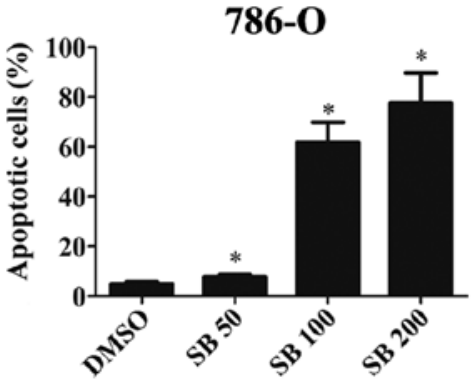

786-O
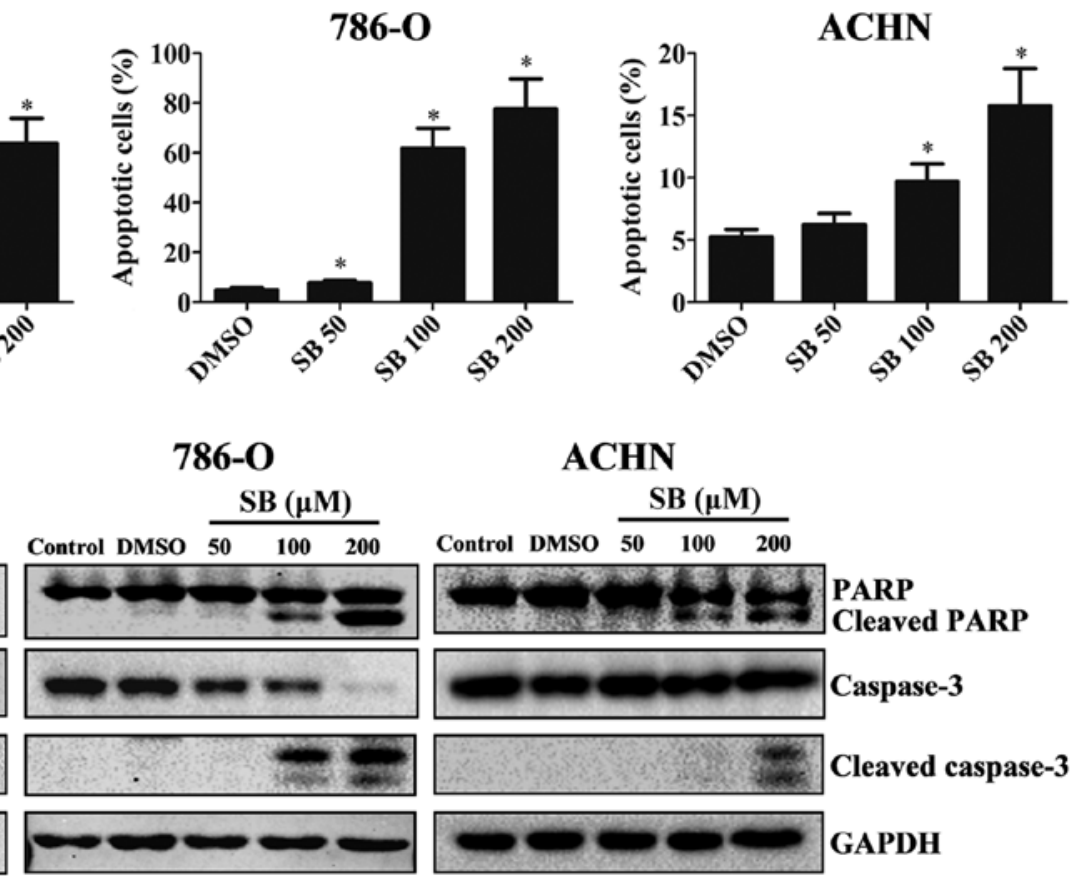

Figure 2. Silibinin induces the apoptosis of RCC cells involving activation of caspase-3 and PARP. (A) Cells were treated with the indicated doses of silibinin (SB) or DMSO (control) for $48 \mathrm{~h}$, and stained with Annexin V and PI. Flow cytometry was performed to detect the percentages of apoptotic cells. (B) Cell lysates were collected for western blot analysis to detect the expression of PARP and caspase-3. GAPDH was used as an internal control. The values represent the mean \pm SD of three independent experiments $\left({ }^{*} \mathrm{P}<0.05\right)$. RCC, renal cell carcinoma.

A

769-P

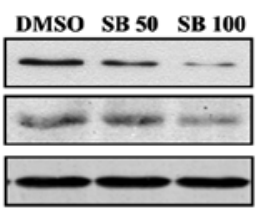

D
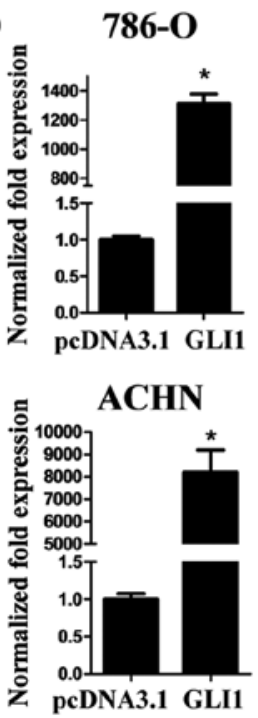

786-O

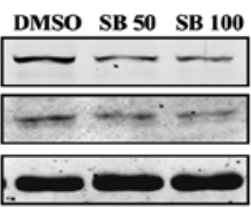

$\mathbf{E}$
ACHN

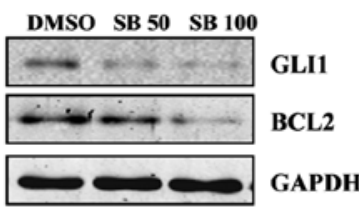

GAPDH
B

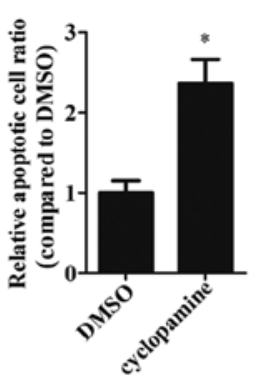

C

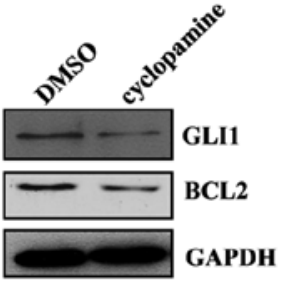

F

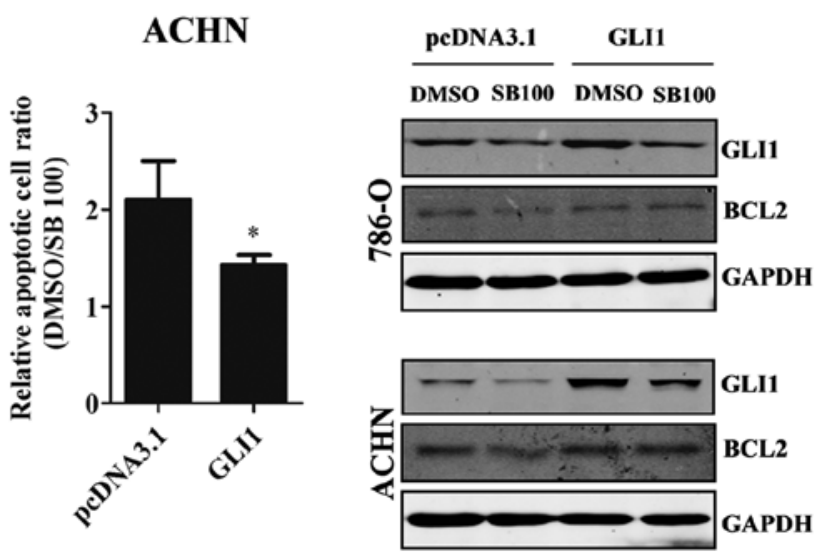

Figure 3. Silibinin induces apoptosis through downregulation of GLI1 and BCL2. (A) The expression levels of GLI1 and downstream BCL2 were detected by western blot analysis after $48 \mathrm{~h}$ of treatment with silibinin (SB). (B) Cells were treated with hedgehog signaling inhibitor cyclopamine (15 $\mu \mathrm{M})$ for $48 \mathrm{~h}$, and apoptosis was detected by flow cytometry. (C) The expression levels of GLI1 and BCL2 were analyzed by western blot analysis after cyclopamine treatment. (D) Cells (786-O and ACHN) were transfected with the pcDNA3.1-GLI1 or pcDNA3.1 (vector control) plasmids for 72 h, and the mRNA expression of GLI1 was analyzed by real-time PCR. (E) After $48 \mathrm{~h}$ of transfection, 786-O and ACHN cells were treated with $100 \mu \mathrm{M}$ silibinin for an additional $48 \mathrm{~h}$, and apoptosis analysis was performed by flow cytometry. (F) The expression levels of GLI1 and BCL2 were detected by western blot analysis. The values represent the mean $\pm \mathrm{SD}$ of three independent experiments $\left({ }^{*} \mathrm{P}<0.05\right)$. 
A

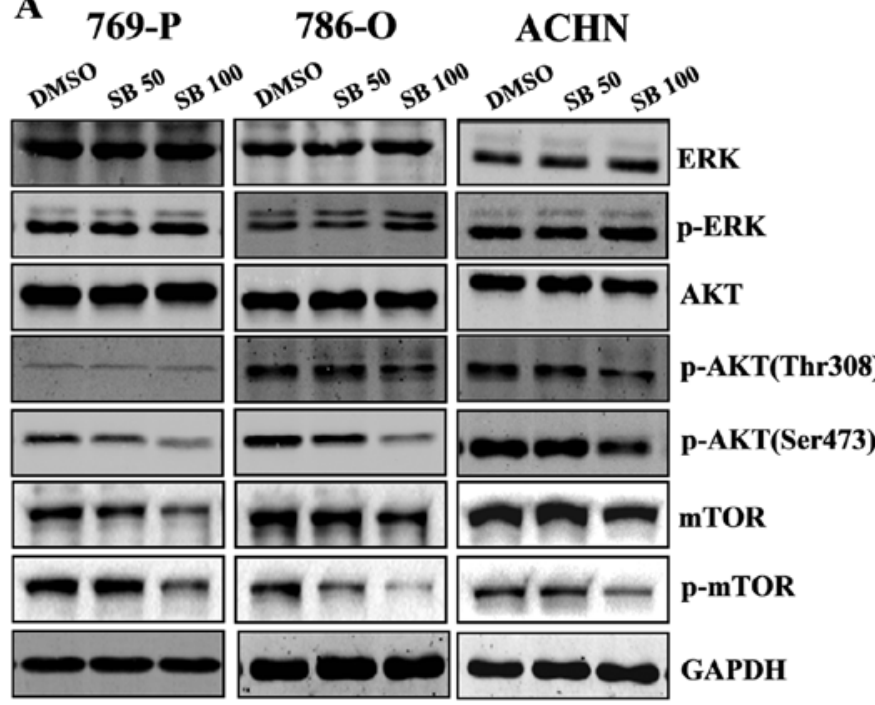

C
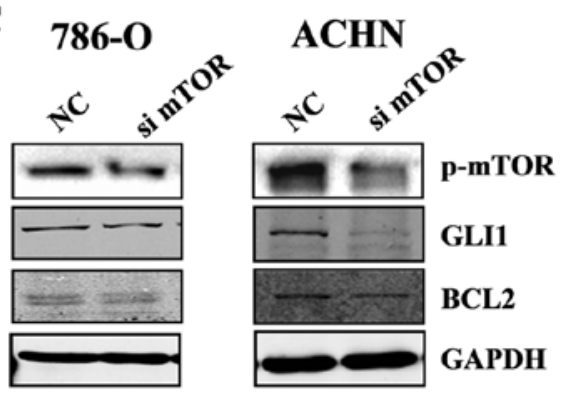

B

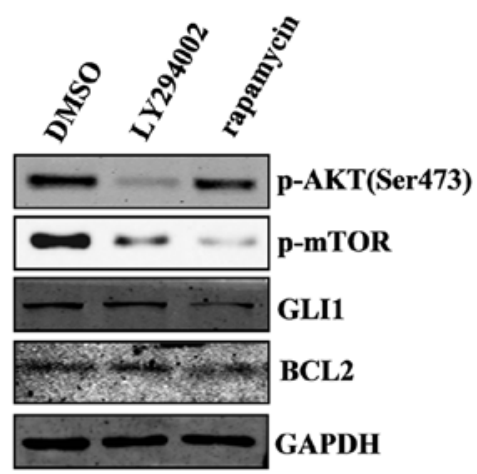

D

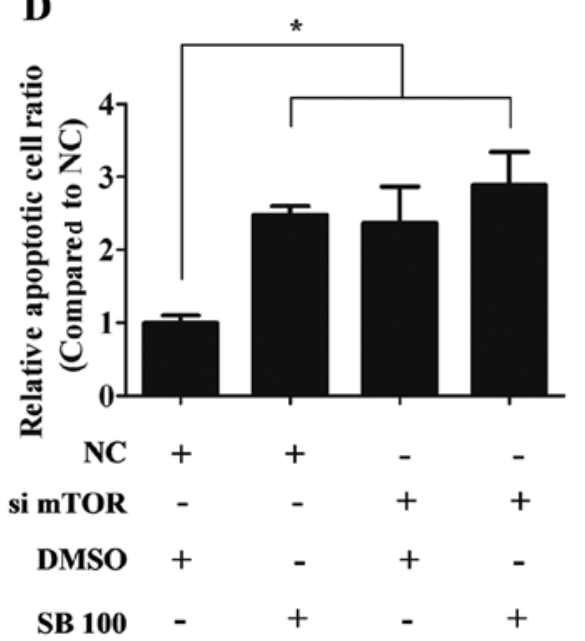

Figure 4. Downregulation of p-mTOR is involved in silibinin-induced GLI1 decrease. (A) RCC cells were treated with different doses of silibinin (SB), and cell lysates were prepared for detection of ERK, AKT and mTOR activities by western blot analysis. (B) Cells (786-O) were treated with LY294002 (PI3K inhibitor, $20 \mu \mathrm{M}$ ) and rapamycin (mTOR inhibitor, $100 \mathrm{nM}$ ), and cell lysates were used to detect GLI1 and BCL2 expression. (C) RCC cells were transfected with mTOR siRNA for $72 \mathrm{~h}$, and GLI1 and BCL2 expression levels were analyzed by western blot analysis. (D) Flow cytometric assay was performed to detect the apoptosis of ACHN cells transfected with mTOR siRNA for $48 \mathrm{~h}$ followed by an additional $48 \mathrm{~h}$ treatment with silibinin or DMSO (control). The values represent the mean $\pm \mathrm{SD}$ of three independent experiments $(\mathrm{P}<0.05)$. RCC, renal cell carcinoma.

Silibinin induces the apoptosis of RCC cells involving activation of caspase-3 and PARP. Since we observed the anti-proliferative effects of silibinin on RCC, we next examined the apoptotic effects of silibinin. RCC 769-P, 786-O and ACHN cells were treated with silibinin (50, 100 and $200 \mu \mathrm{M}$ ) or DMSO (control) for $48 \mathrm{~h}$. Cells were then collected for flow cytometric assay and western blot analysis. The percentages of apoptotic cells after treatment with different dosages of silibinin $(50,100$ and $200 \mu \mathrm{M})$ vs. the control cells were 5.77/22.72/51.10 vs. $4.91 \%$ (769-P), 7.79/61.9/77.69 vs. $5.05 \%$ (786-O), 6.23/9.71/15.77 vs. $5.24 \%$ $(\mathrm{ACHN})$, respectively $(\mathrm{P}<0.05)$ (Fig. $2 \mathrm{~A})$. Western blot analysis data showed that cleaved subunits of caspase-3 and PARP were increased upon silibinin treatment in a dosedependent manner (Fig. 2B), indicating the activation of the caspase cascade by silibinin. Taken together, our results demonstrated that silibinin induces RCC cell apoptosis via activation of caspase cascade signaling.

Silibinin induces apoptosis through downregulation of GLII and BCL2. Since we demonstrated that silibinin treatment inhibits cell proliferation, the underlying mechanism was investigated. As shown in Fig. 3A, silibinin markedly downregulated GLI1 expression in all three RCC cell lines in a dose-dependent manner, and BCL2, the downstream molecule of GLI1, was also decreased. As known, GLI1 plays an important role in cancer development and progression. In order to detect the function of GLI1 in RCC, we used cyclopamine, a potent Hh signaling inhibitor. The results showed that cyclopamine induced the apoptosis of 769-P cells (Fig. 3B), while the levels of GLI1 and BCL2 were reduced (Fig. 3C). When the GLI1-overexpressing plasmid was transfected into 786-O and ACHN cells, the apoptosis and reduced BCL2 expression induced by silibinin was partially reversed (Fig. 3D-F), suggesting that the GLI1-BCL2 pathway participates in the silibinin-induced apoptosis of RCC cells.

Downregulation of p-mTOR is involved in the silibinin-induced GLII decrease. To further investigate the mechanisms of the silibinin-induced decrease in GLI1, we detected the GLI1-associated pathway which has been previously reported to regulate GLI1 expression. Western blot results showed that $\mathrm{p}$-AKT, $\mathrm{p}$-mTOR but not $\mathrm{p}$-ERK were downregulated after the treatment with silibinin (Fig. 4A). Additionally, only the p-mTOR inhibitor (rapamycin, $100 \mathrm{nM}$ ) but not the p-AKT inhibitor (LY294002, $20 \mu \mathrm{M}$ ) could inhibit GLI1 and BCL2 expression in the 786-O cells (Fig. 4B). Furthermore, knockdown of mTOR by siRNA 
$\mathbf{A}$

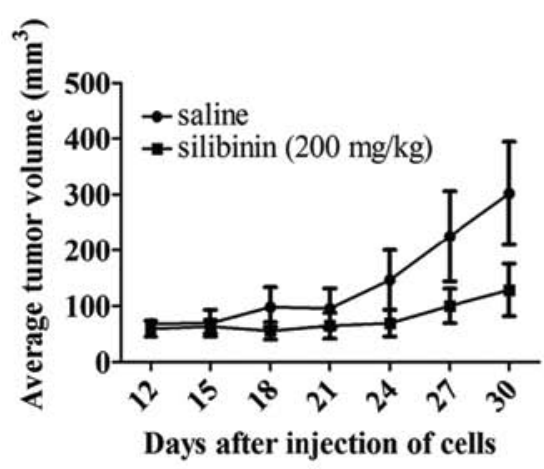

B

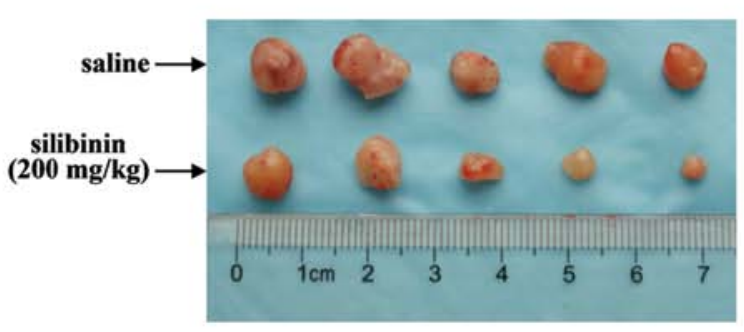

C

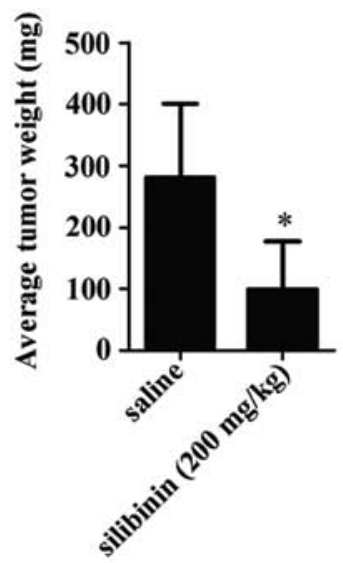

D

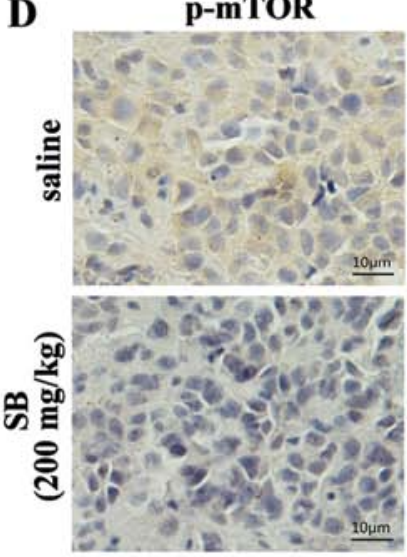

\section{GLI1}

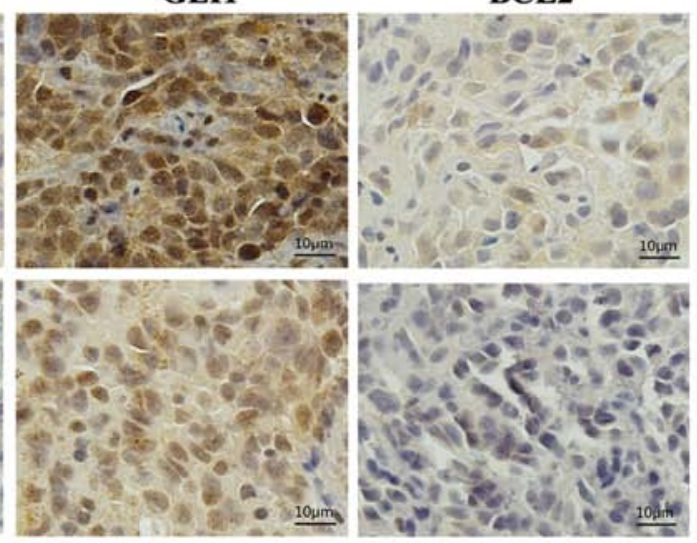

\section{BCL2}

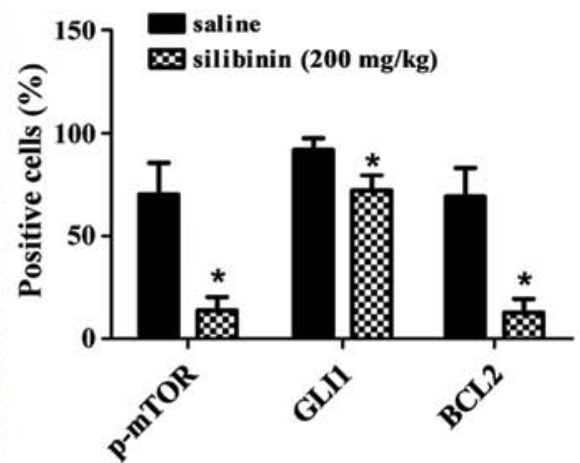

Figure 5. Silibinin inhibits the growth of RCC xenografts in vivo. Cells (786-O) were subcutaneously injected into male BALB/c (nu/nu) mice as described in Materials and methods. (A) The growth of tumors were analyzed. (B) The tumors were isolated and captured. (C) The tumors were weighed with electronic scales. (D) The expression levels of p-mTOR, GLI1 and BCL2 were detected by immunohistochemical analysis, and the percentage of positively stained cells was quantified. The values represent the mean $\pm \mathrm{SD}$ of five samples from individual mice in each group $\left({ }^{*} \mathrm{P}<0.05\right)$. RCC, renal cell carcinoma.

in the 786-O and ACHN cells reduced GLI1 and BCL2 expression (Fig. 4C), indicating that the mTOR pathway regulated GLI1 expression in the RCC cells. When knockdown of mTOR by siRNA was combined with silibinin treatment or DMSO (control) in ACHN cells, we found this combination did not increase the percentage of apoptotic cells compared with silibinin alone or mTOR knockdown alone (Fig. 4D), which implied that the silibinin-induced apoptosis of RCC cells was mediated by mTOR. Taken together, our results indicate that silibinin inhibits GLI1 expression via reduction of mTOR activity.

Silibinin inhibits the growth of RCC xenografts in vivo. To further evaluate the anticancer effects of silibinin in vivo, we chose 786-O cells, which have a high potential for tumor formation, as a model system in vivo. Silibinin $(200 \mathrm{mg} / \mathrm{kg})$ inhibited tumor growth compared with the control group in vivo (Fig. $5 \mathrm{~A}$ and $\mathrm{B}$ ). After 30 days, the average tumor weight of the silibinin-treated group was $98.8 \pm 77.6 \mathrm{mg}$ while the control group was $281.22 \pm 118.87 \mathrm{mg}(\mathrm{P}<0.05)$ (Fig. 5C). Immunohistochemistry assay showed that the expression levels of p-mTOR, GLI1 and BCL2 were decreased in the silibinin $(200 \mathrm{mg} / \mathrm{kg})$ group compared with the saline group (control) in the xenograft samples, which was consistent with the results observed in vitro (Fig. 5D).

\section{Discussion}

There have been only a limited number of studies on the apoptotic effects of silibinin on RCC cells. Our previous studies showed the apoptotic and anti-metastatic effects of silibinin on RCC cells, in which downregulated p-ERK was observed after the treatment of silibinin $(27,28)$. However, in our present study, no significant change was detected in p-ERK expression. Such disparate findings from our results could be due to the difference in cell type used (we used RCC cell line Caki-1 in our previous study, while 769-P, 786-O and OS-RC-2 cell lines were used in our present study), implying that there may be fundamental differences in the individual gene expression pattern among various cell lines. Therefore, precautions should be taken when extrapolating results from one to another study. More recently, we reported the role of autophagy and the AMPK/mTOR pathway in the silibinin-induced anti-metastatic effects on RCC cells (29). As known, when cells are subjected to adverse stress, such as nutrient starvation or chemical agents, cancer cells may trigger an autophagic response followed by degradation of unnecessary molecules or organelles to prevent cells from death. On the other hand, treatment with many anticancer reagents or ionizing radiation, has been shown to induce autophagic cell death, directly leading to the inhibition of 
cancer cell growth (30-32). Silibinin has been reported to induce autophagic death in cervical and breast cancer $(33,34)$. Another study indicated that inhibition of autophagy with a specific inhibitor enhanced cell death, suggesting a cytoprotective function of autophagy in silibinin-treated cells (35). Thus, there is considerable interest in elucidating the mechanisms of interplay between autophagy and apoptosis induced by silibinin, which clearly requires further research.

The Hh pathway was proven to play a crucial role in pancreatic cancer tumorigenesis in early and late stages, and the maintenance of $\mathrm{Hh}$ signaling is important for aberrant proliferation and tumorigenesis (9). Our results confirmed that GLI1 sustained the proliferation of RCC, and inhibition of GLI1 by cyclopamine induced apoptosis by downregulation of BCL2, which was consistent with previously published results (12). We first documented that silibinin effectively decreased the expression of GLI1 in a dose-dependent manner and induced apoptosis by downregulating the expression of BCL2 in RCC. Overexpression of GLI1 could partially reverse the apoptosis induced by silibinin, which implied that GLI1 is a regulator for the potential therapeutic application of silibinin against mRCC.

As the downstream transcriptional factor of the $\mathrm{Hh}$ pathway, GLI1 plays a key role in regulating cancer progression not only in an SMO-dependent manner but also in an SMO-independent manner. The canonical SMO-dependent pathway was found to be activated by the binding of ligand $\mathrm{HH}$ to the membrane receptor PTC, which triggered another membrane receptor SMO disassociated from PTC and activated GLI1. However, Desch et al confirmed the autonomous role of GLI in B-cell chronic lymphocytic leukemia (CLL) cell apoptosis independent of SMO (36). The well known SMO-independent pathway includes the AKT pathway (37), MAPK/ERK pathway (38) and KRAS pathway (39). Wang et al found that activation of the mTOR/S6K1 pathway could enhance GLI1 transcriptional activity and oncogenic function through S6K1-mediated GLI1 phosphorylation at Ser84, which released GLI1 from its endogenous inhibitor $\mathrm{SuFu}(40)$. In order to explore the mechanisms involved in the silibinin-induced GLI1 downregulation, we detected p-ERK, p-AKT and p-mTOR expression which have been reported to regulate GLI1 expression after silibinin treatment in RCC. The results showed that $\mathrm{p}$-AKT and p-mTOR were downregulated but p-ERK had no significant change. Then we treated RCC cells with inhibitors of PI3K (LY294002, $20 \mu \mathrm{M}$ ) and p-mTOR (rapamycin, $100 \mathrm{nM}$ ), followed by detection of GLI1 protein expression. However, only the mTOR inhibitor decreased GLI1 expression in RCC. Meanwhile, the results of the knockdown of mTOR by siRNA also supported the conclusion, indicating that GLI1 is regulated by the mTOR pathway in RCC. As known, mTOR has two existing complex forms exerting various effects, mTORC1 (raptor) and mTORC2 (rictor). mTORC1 is regulated by AKT whereas mTORC2 is the upstream of AKT. Our results indicated that GLI1 might be potentially regulated by mTORC 2 but not mTORC1. However, the exact evidence remains to be explored in further studies.

The activation of the mTOR pathway has been found in RCC and is correlated with high grade and poor prognostic patient features $(41,42)$. Recently, the mTOR pathway has been considered as one of the most important targets for mRCC therapy, and mTOR antagonists rapamycin and three analogs of rapamycin (temsirolimus, everolimus and deferolimus) have undergone clinical evaluation as cancer therapeutics. It was reported that silibinin could dephosphorylate mTOR and its effectors ribosomal protein S6 kinase (p70S6K) and eukaryotic initiation factor 4E-binding protein-1 (4E-BP1) and suppress HIF-1 $\alpha$ accumulation (43). Silibinin inhibited colon cancer stem-like cell self-renewal and sphere formation by suppressing the PP2Ac/AKT Ser473/mTOR pathway (44). Our data also supported that silibinin could reduce the activation of the mTOR pathway in RCC. However, the mechanisms that mediate the silibinin-regulated mTOR pathway still need to be identified.

In conclusion, our in vitro and in vivo results first demonstrated that silibinin-induced apoptosis of RCC cells was mediated by the regulation of the mTOR-GLI1-BCL2 pathway. This finding also implies that GLI1 is a novel regulator mediated by silibinin for potential therapeutic application in $\mathrm{mRCC}$, providing a basis for future clinical trials of silibinin for the treatment of patients with mRCC.

\section{Acknowledgements}

This study was supported by the National Natural Science Foundation of China (NSFC no. 81072107 to Lei Li and NSFC no. 81101936 to Jin Zeng) and China ' 863 ' program (SS2014AA020607).

\section{References}

1. Siegel R, Ma J, Zou Z and Jemal A: Cancer statistics, 2014. CA Cancer J Clin 64: 9-29, 2014.

2. Motzer RJ, Bander NH and Nanus DM: Renal-cell carcinoma. N Engl J Med 335: 865-875, 1996.

3. Johnsen JA and Hellsten S: Lymphatogenous spread of renal cell carcinoma: An autopsy study. J Urol 157: 450-453, 1997.

4. Fyfe G, Fisher RI, Rosenberg SA, Sznol M, Parkinson DR and Louie AC: Results of treatment of 255 patients with metastatic renal cell carcinoma who received high-dose recombinant interleukin-2 therapy. J Clin Oncol 13: 688-696, 1995.

5. Yang JC, Sherry RM, Steinberg SM, Topalian SL, Schwartzentruber DJ, Hwu P, Seipp CA, Rogers-Freezer L, Morton KE, White DE, et al: Randomized study of high-dose and low-dose interleukin-2 in patients with metastatic renal cancer. J Clin Oncol 21: 3127-3132, 2003.

6. McDermott DF, Regan MM, Clark JI, Flaherty LE, Weiss GR, Logan TF, Kirkwood JM, Gordon MS, Sosman JA, Ernstoff MS, et al: Randomized phase III trial of high-dose interleukin-2 versus subcutaneous interleukin-2 and interferon in patients with metastatic renal cell carcinoma. J Clin Oncol 23: 133-141, 2005.

7. Nüsslein-Volhard C and Wieschaus E: Mutations affecting segment number and polarity in Drosophila. Nature 287: 795-801, 1980

8. Ingham PW and McMahon AP: Hedgehog signaling in animal development: Paradigms and principles. Genes Dev 15: 3059-3087, 2001.

9. Thayer SP, di Magliano MP, Heiser PW, Nielsen CM, Roberts DJ, Lauwers GY, Qi YP, Gysin S, Fernández-del Castillo C, Yajnik V, et al: Hedgehog is an early and late mediator of pancreatic cancer tumorigenesis. Nature 425: 851-856, 2003.

10. Sanchez P, Hernández AM, Stecca B, Kahler AJ, DeGueme AM, Barrett A, Beyna M, Datta MW, Datta S and Ruiz i Altaba A: Inhibition of prostate cancer proliferation by interference with SONIC HEDGEHOG-GLI1 signaling. Proc Natl Acad Sci USA 101: 12561-12566, 2004.

11. Qualtrough D, Buda A, Gaffield W, Williams AC and Paraskeva C: Hedgehog signalling in colorectal tumour cells: Induction of apoptosis with cyclopamine treatment. Int J Cancer 110: 831-837, 2004. 
12. Han ME, Lee YS, Baek SY, Kim BS, Kim JB and Oh SO Hedgehog signaling regulates the survival of gastric cancer cells by regulating the expression of Bcl-2. Int J Mol Sci 10: 3033-3043, 2009.

13. Hegde GV, Peterson KJ, Emanuel K, Mittal AK, Joshi AD, Dickinson JD, Kollessery GJ, Bociek RG, Bierman P, Vose JM, et al: Hedgehog-induced survival of B-cell chronic lymphocytic leukemia cells in a stromal cell microenvironment: A potential new therapeutic target. Mol Cancer Res 6: 1928-1936, 2008.

14. Von Hoff DD, LoRusso PM, Rudin CM, Reddy JC, Yauch RL, Tibes R, Weiss GJ, Borad MJ, Hann CL, Brahmer JR, et al: Inhibition of the hedgehog pathway in advanced basal-cell carcinoma. N Engl J Med 361: 1164-1172, 2009.

15. LoRusso PM, Rudin CM, Reddy JC, Tibes R, Weiss GJ, Borad MJ, Hann CL, Brahmer JR, Chang I, Darbonne WC, et al: Phase I trial of hedgehog pathway inhibitor vismodegib (GDC-0449) in patients with refractory, locally advanced or metastatic solid tumors. Clin Cancer Res 17: 2502-2511, 2011.

16. Kim DJ, Kim J, Spaunhurst K, Montoya J, Khodosh R, Chandra K, Fu T, Gilliam A, Molgo M, Beachy PA, et al: Open-label, exploratory phase II trial of oral itraconazole for the treatment of basal cell carcinoma. J Clin Oncol 32: 745-751, 2014.

17. Dormoy V, Danilin S, Lindner V, Thomas L, Rothhut S, Coquard C, Helwig JJ, Jacqmin D, Lang H and Massfelder T: The sonic hedgehog signaling pathway is reactivated in human renal cell carcinoma and plays orchestral role in tumor growth. Mol Cancer 8: 123, 2009.

18. Singh RP, Raina K, Deep G, Chan D and Agarwal R: Silibinin suppresses growth of human prostate carcinoma PC-3 orthotopic xenograft via activation of extracellular signal-regulated kinase $1 / 2$ and inhibition of signal transducers and activators of transcription signaling. Clin Cancer Res 15: 613-621, 2009.

19. Wu KJ, Zeng J, Zhu GD, Zhang LL, Zhang D, Li L, Fan JH, Wang XY and He DL: Silibinin inhibits prostate cancer invasion, motility and migration by suppressing vimentin and MMP-2 expression. Acta Pharmacol Sin 30: 1162-1168, 2009.

20. Wu K, Ning Z, Zeng J, Fan J, Zhou J, Zhang T, Zhang L, Chen Y, Gao Y, Wang B, et al: Silibinin inhibits $\beta$-catenin/ZEB1 signaling and suppresses bladder cancer metastasis via dual-blocking epithelial-mesenchymal transition and stemness. Cell Signal 25 2625-2633, 2013.

21. Zeng J, Sun Y, Wu K, Li L, Zhang G, Yang Z, Wang Z, Zhang D, Xue Y, Chen Y, et al: Chemopreventive and chemotherapeutic effects of intravesical silibinin against bladder cancer by acting on mitochondria. Mol Cancer Ther 10: 104-116, 2011.

22. Tyagi A, Singh RP, Ramasamy K, Raina K, Redente EF, Dwyer-Nield LD, Radcliffe RA, Malkinson AM and Agarwal R: Growth inhibition and regression of lung tumors by silibinin: Modulation of angiogenesis by macrophage-associated cytokines and nuclear factor-kappaB and signal transducers and activators of transcription 3. Cancer Prev Res (Phila) 2: 74-83, 2009.

23. Kaur M, Velmurugan B, Tyagi A, Deep G, Katiyar S, Agarwal C and Agarwal R: Silibinin suppresses growth and induces apoptotic death of human colorectal carcinoma LoVo cells in culture and tumor xenograft. Mol Cancer Ther 8: 2366-2374, 2009.

24. Singh RP, Gu M and Agarwal R: Silibinin inhibits colorectal cancer growth by inhibiting tumor cell proliferation and angiogenesis. Cancer Res 68: 2043-2050, 2008.

25. Li L, Zeng J, Gao Y and He D. Targeting silibinin in the antiproliferative pathway. Expert Opin Investig Drugs 19: 243-255, 2010.

26. Cheung CW, Taylor PJ, Kirkpatrick CM, Vesey DA, Gobe GC, Winterford C, Nicol DL and Johnson DW: Therapeutic value of orally administered silibinin in renal cell carcinoma: Manipulation of insulin-like growth factor binding protein-3 levels. BJU Int 100: 438-444, 2007.

27. Li L, Gao Y, Zhang L, Zeng J, He D and Sun Y: Silibinin inhibits cell growth and induces apoptosis by caspase activation, down-regulating survivin and blocking EGFR-ERK activation in renal cell carcinoma. Cancer Lett 272: 61-69, 2008.
28. Liang L, Li L, Zeng J, Gao Y, Chen YL, Wang ZQ, Wang XY, Chang LS and He D: Inhibitory effect of silibinin on EGFR signal-induced renal cell carcinoma progression via suppression of the EGFR/MMP-9 signaling pathway. Oncol Rep 28: 999-1005, 2012.

29. Li F, Ma Z, Guan Z, Chen Y, Wu K, Guo P, Wang X, He D and Zeng J: Autophagy induction by silibinin positively contributes to its anti-metastatic capacity via AMPK/mTOR pathway in renal cell carcinoma. Int J Mol Sci 16: 8415-8429, 2015.

30. Green DR, Galluzzi L and Kroemer G: Cell biology. Metabolic control of cell death. Science 345: 1250256, 2014.

31. Green DR and Levine B: To be or not to be? How selective autophagy and cell death govern cell fate. Cell 157: 65-75, 2014.

32. Navarro-Yepes J, Burns M, Anandhan A, Khalimonchuk O, del Razo LM, Quintanilla-Vega B, Pappa A, Panayiotidis MI and Franco R: Oxidative stress, redox signaling, and autophagy: Cell death versus survival. Antioxid Redox Signal 21: 66-85, 2014

33. Fan S, Li L, Chen S, Yu Y, Qi M, Tashiro S, Onodera S and Ikejima T: Silibinin induced-autophagic and apoptotic death is associated with an increase in reactive oxygen and nitrogen species in HeLa cells. Free Radic Res 45: 1307-1324, 2011.

34. Zheng N, Zhang P, Huang H, Liu W, Hayashi T, Zang L, Zhang Y, Liu L, Xia M, Tashiro SI, Onodera S and Ikejima T: ERalpha down-regulation plays a key role in silibinin-induced autophagy and apoptosis in human breast cancer MCF-7 cells. J Pharmacol Sci: May 12, 2015 (Epub ahead of print).

35. Kauntz H, Bousserouel S, Gossé F and Raul F: Silibinin triggers apoptotic signaling pathways and autophagic survival response in human colon adenocarcinoma cells and their derived metastatic cells. Apoptosis 16: 1042-1053, 2011.

36. Desch P, Asslaber D, Kern D, Schnidar H, Mangelberger D, Alinger B, Stoecher M, Hofbauer SW, Neureiter D, Tinhofer I, et al: Inhibition of GLI, but not Smoothened, induces apoptosis in chronic lymphocytic leukemia cells. Oncogene 29: 4885-4895, 2010.

37. Stecca B, Mas C, Clement V, Zbinden M, Correa R, Piguet V, Beermann F and Ruiz I Altaba A: Melanomas require HEDGEHOG-GLI signaling regulated by interactions between GLI1 and the RAS-MEK/AKT pathways. Proc Natl Acad Sci USA 104: 5895-5900, 2007.

38. Seto M, Ohta M, Asaoka Y, Ikenoue T, Tada M, Miyabayashi K, Mohri D, Tanaka Y, Ijichi H, Tateishi K, et al: Regulation of the hedgehog signaling by the mitogen-activated protein kinase cascade in gastric cancer. Mol Carcinog 48: 703-712, 2009

39. Nolan-Stevaux O, Lau J, Truitt ML, Chu GC, Hebrok M, Fernández-Zapico ME and Hanahan D: GLI1 is regulated through Smoothened-independent mechanisms in neoplastic pancreatic ducts and mediates PDAC cell survival and transformation. Genes Dev 23: 24-36, 2009.

40. Wang Y, Ding Q, Yen CJ, Xia W, Izzo JG, Lang JY, Li CW, Hsu JL, Miller SA, Wang X, et al: The crosstalk of mTOR/S6K1 and Hedgehog pathways. Cancer Cell 21: 374-387, 2012.

41. Robb VA, Karbowniczek M, Klein-Szanto AJ and Henske EP. Activation of the mTOR signaling pathway in renal clear cell carcinoma. J Urol 177: 346-352, 2007.

42. Pantuck AJ, Seligson DB, Klatte T, Yu H, Leppert JT, Moore L, O'Toole T, Gibbons J, Belldegrun AS and Figlin RA: Prognostic relevance of the mTOR pathway in renal cell carcinoma: implications for molecular patient selection for targeted therapy. Cancer 109: 2257-2267, 2007.

43. García-Maceira $P$ and Mateo $J:$ Silibinin inhibits hypoxia-inducible factor-1alpha and mTOR/p70S6K/4E-BP1 signalling pathway in human cervical and hepatoma cancer cells: Implications for anticancer therapy. Oncogene 28: 313-324, 2009.

44. Wang JY, Chang CC, Chiang CC, Chen WM and Hung SC: Silibinin suppresses the maintenance of colorectal cancer stem-like cells by inhibiting PP2A/AKT/mTOR pathways. J Cell Biochem 113: 1733-1743, 2012. 